\title{
EVALUASI ADVERSE DRUG REACTIONS DAN EFEKTIVITAS PENGGUNAAN KETOROLAK PADA PASIEN PASCA BEDAH SARAF DI RUMAH SAKIT UMUM PENDIDIKAN DR. WAHIDIN SUDIROHUSODO MAKASSAR
}

\author{
Hendra Herman "), Zullies Ikawati ${ }^{* *}$, Rina Handayani ${ }^{* *}$ \\ ${ }^{*}$ Fakultas Farmasi Universitas Muslim Indonesia \\ ${ }^{\star *}$ Fakultas Farmasi Universitas Gadjah Mada Yogyakarta \\ Email : noncee2307@gmail.com
}

\begin{abstract}
Pain is often experienced by patients treated in the hospital and is the most frequently reported events in post-surgical patients. Ketorolac associated with the incidence of adverse reactions include, the incidence of acute renal failure and bleeding disorders. The purpose of the study was to observe and report on the profile of adverse reactions include the use of ketorolac on renal function and hemostasis as well as the effectiveness of the analgesic ketorolac. A total of 20 patients who received ketorolac compared to the value of the glomerular filtration rate (GFR), bleeding time (BT), Blood Clotting Time (CT), prothrombin time (PT) and International Normalized Ratio (INR) between before and after patients received ketorolac. Compared to the value of the Visual Analog Scale (VAS) ranging V day I to day administration of ketorolac. One of 20 patients (5\%) who use ketorolac for 5 days had decreased GFR by $66.70 \%$.. Whereas for hemostasis testing showed that ketorolac can influence hemostatic seen from increasing on $B T(0,04 ; p<0,05)$, CT $(0,02 ; p<0,05), P T$ value $(0,03, p<0,05)$, as well as an increase in INR value $(0,03$; $p<0: 05)$ but still in normal range. Comparison of the mean VAS score from day one to day five showed that administration of ketorolac can reduce pain and disappeared on day 4 , where VAS values between days 4 and 5 showed no statistical difference $(0,56 ; p>0,05)$. Conclusion. incidence of renal damage incident occurred at $5 \%$, and may affect hemostatic function in patients. Resolution of pain may occur at day 4 ketorolac administration.
\end{abstract}

Key word : Evaluation, Adverse Effects, Effectiveness, Ketorolac, Post-Nerve Surgical Patient

\section{PENDAHULUAN}

Nyeri seringkali dialami oleh pasien-pasien yang dirawat di rumah sakit dan merupakan kejadian yang paling sering dilaporkan pada pasien pasca bedah. (Vivian et al., 2009) Penanganan terhadap nyeri merupakan faktor yang penting dalam meningkatkan kualitas hidup pasien utamanya pada pasien pasca bedah (Scottish Intercollegiate Guidelines Network, 2004). Pasien akan merasakan nyeri setelah hilangnya efek anastesi yang digunakan pada 
proses pembedahan. Penanganan nyeri pada pasien pasca bedah sangat diperlukan untuk meningkatkan kualitas hidup pasien meliputi lama inap pasien yang berhubungan dengan biaya perawatan dan penderitaan pasien akibat rasa nyeri tersebut. Ketorolak digunakan sebagai analgetik untuk nyeri akut pasca operasi yang penggunaannya dibatasi hanya sampai maksimal 5 hari. Ketorolak tersedia dalam bentuk parenteral (intravena dan intramuscular) serta sediaan oral. Khusus untuk sediaan oral hanya diperuntukkan sebagai terapi lanjutan setelah parenteral dan penggunaan totalnya (parenteral dan oral) tidak boleh melebihi dari 5 hari. Pembatasan pada durasi penggunaan obat dihubungkan dengan kejadian adverse reactions dari ketorolak meliputi pendarahan GI, gangguan pendarahan, dan kejadian gagal ginjal akut (Lacy et al., 2008).

$$
\text { Meskipun penggunaan }
$$

ketorolak banyak digunakan untuk mengatasi nyeri selama dalam kurun waktu 20 tahun terakhir (Schug dan Manopas, 2007), efektivitas dan adverse reaction yang mungkin ditimbulkan tetap perlu dikaji agar dapat memperkuat bukti penggunaannya di klinik. Selain itu kurangnya data penggunaan efektivitas dan adverse reactions di Indonesia menuntut peneliti untuk melaksanakan penelitian ini.

Penelitian ini bertujuan untuk mengamati dan melaporkan profil penggunaan ketorolak meliputi adverse reactions (gangguan fungsi ginjal dan gangguan hemostasis) dan efektivitas menggunakan VAS pada pasien pasca bedah saraf di rumah sakit umum pendidikan dr. Wahidin Sudirohusodo Makassar.

\section{METODE PENELITIAN}

\section{Subyek Penelitian}

Penelitian ini diikuti oleh 20 pasien yang telah menjalani bedah saraf dan di rawat di bangsal perawatan pasca bedah saraf RSUP dr. Wahidin Sudirohusodo Makassar.

\section{Instrumen Penelitian}

Instrumen yang digunakan adalah rekam medik pasien untuk melihat data laboratorium meliputi nilai Laju Filtrasi Glomerulus (GFR), Waktu Perdarahan (BT), Waktu Pembekuan Darah (CT), Waktu Protrombin (PT), dan International Normalized Ratio (INR). Untuk menilai nyeri, digunakan formulir Visual Analog Scale (VAS) yang telah dimodifikasi untuk kepentingan penelitian. 
Jalan Penelitian

Tahap persiapan

Pada tahap ini, dilakukan persiapan unutk menunjang berjalannya penelitian meliputi, penelusuran pustaka dan pembuatan proposal serta pengurusan persetujuan etik. Persetujuan etik didapatkan dari Komisi Etik Penelitian Kesehatan Fakultas Kedokteran Universitas Hasanuddin Makassar.

Penelitian di Bangsal Perawatan Bedah Saraf RSUP dr. Wahidin Sudirohusodo Makassar

Setelah pasien menyetujui untuk berpartisipasi dalam penelitian dengan menandatangani form persetujuan, kemudian peneliti melakukan pengambilan data awal meliputi nama, usia, berat badan, tinggi badan, nomor rekam medik, diagnosa, jenis pembedahan yang akan dilakukan, dan riwayat penggunaan obat oleh pasien. Data yang kurang kemudian didapatkan dari wawancara langsung ke pasien.

Parameter untuk menilai adverse reactions yaitu nilai kreatinin, waktu perdarahan (BT), waktu pembekuan darah (CT), waktu protrombin (PT), dan International Normalized ratio (INR) di dapatkan dari laboratorium klinik RSUP $d r$.
Wahidin Sudirohusodo dengan pengambilan sampel sebanyak 2 kali untuk tiap-tiap pasien, yaitu pertama sebelum pasien menjalani pembedahan dan setelah 5 hari pemberian ketorolak. Nilai kreatinin kemudian digunakan untuk menghitung laju filtrasi glomerulus (GFR) menggunakan rumus Cokroft and Goult.

Untuk menilai efektivitas, pasien akan diinstruksikanp untuk mengisi lembar Visual Analog Scale (VAS) setiap hari selama 5 hari pemberian ketorolak. Kemudian hasilnya kemudian dikonversikan ke dalam bentuk angka.

\section{Analisis Hasil Penelitian}

Data yang didapatkan kemudian disusun dan dikelompokkan berdasarkan analisis yang akan dilakukan. Uji normalitas yang digunakan untuk semua variabel adalah uji Shapiro-Wilk. Untuk variabel-variabel pengamatan adverse reaction, digunakan uji Wilcoxon untuk melihat perbedaan rerata nilai antara parameter pra dan pasca pemberian ketorolak. Untuk skor VAS, dibandingkan menggunakan uji Friedman sebagai alternatif uji Anava. Kemudian dilakukan uji post-hoc menggunakan uji Wilcoxon. 


\section{HASIL PENELITIAN}

Tabel 1. Analisis Perbandingan Nilai GFR Pasien antara Kondisi Pra Dan Pasca Pemberian Ketorolak Selama 5 Hari

\begin{tabular}{lcccc}
\hline \multicolumn{1}{c}{ Kelompok } & N & Median (minimum-maksimum) & Rerata \pm S.E. & $\boldsymbol{P}$ \\
\hline $\begin{array}{l}\text { GFR Pra pemberian } \\
\text { ketorolak }\end{array}$ & 20 & $95,14(72,97-181,02)$ & $104,68 \pm 6,34$ & 0,68 \\
$\begin{array}{l}\text { GFR Pasca pemberian } \\
\text { ketorolak }\end{array}$ & 20 & $97,43(60,34-198,33)$ & $105,151 \pm 7,20$ & \\
\hline
\end{tabular}

Tabel 2. Analisis Perbandingan Nilai BT Pasien antara Kondisi Pra dan Pasca Pemberian Ketorolak Selama 5 Hari

\begin{tabular}{lcccc}
\hline \multicolumn{1}{c}{ Kelompok } & N & Median (minimum-maksimum) & Rerata + S.E. & P \\
\hline $\begin{array}{l}\text { BT Pra pemberian } \\
\text { ketorolak }\end{array}$ & 20 & $3(2,00-3,30)$ & $2,66 \pm 0,11$ & 0,04 \\
$\begin{array}{l}\text { BT Pasca pemberian } \\
\text { ketorolak }\end{array}$ & 20 & $3(2,00-4,00)$ & $3,02 \pm 0,10$ & \\
\hline
\end{tabular}

Tabel 3. Analisis Perbandingan Nilai CT Pasien antara Kondisi Pra dan Pasca Pemberian Ketorolak Selama 5 Hari

\begin{tabular}{lcccc}
\hline \multicolumn{1}{c}{ Kelompok } & N & Median (minimum-maksimum) & Rerata + S.E. & p \\
\hline $\begin{array}{l}\text { CT Pra pemberian } \\
\text { ketorolak }\end{array}$ & 20 & $7,00(7,00-9,00)$ & $7,47 \pm 0,13$ & 0,02 \\
$\begin{array}{l}\text { CT Pasca pemberian } \\
\text { ketorolak }\end{array}$ & 20 & $8,00(7,00-9,00)$ & $7,95 \pm 0,09$ & \\
\hline
\end{tabular}

Tabel 4. Analisis Perbandingan Nilai PT dan INR Pasien antara Kondisi Pra dan Pasca Pemberian Ketorolak Selama 5 Hari

\begin{tabular}{lcccc}
\hline \multicolumn{1}{c}{ Kelompok } & N & Median (minimum-maksimum) & Rerata + S.E. & p \\
\hline $\begin{array}{l}\text { PT Pra pemberian } \\
\text { ketorolak }\end{array}$ & 20 & $10,9(9,3-15,4)$ & $11,47 \pm 0,36$ & 0,03 \\
$\begin{array}{l}\text { PT Pasca pemberian } \\
\text { ketorolak }\end{array}$ & 20 & $11,1(10,1-15,9)$ & $11,73 \pm 0,34$ & \\
\hline $\begin{array}{l}\text { INR Pra pemberian } \\
\text { ketorolak }\end{array}$ & 20 & $0,9(0,76-1,2)$ & $0,94 \pm 0,03$ & 0,03 \\
$\begin{array}{l}\text { INR Pasca pemberian } \\
\text { ketorolak }\end{array}$ & 20 & $0,97(0,8-1,5)$ & $0,99 \pm 0,04$ & \\
\hline
\end{tabular}

Tabel 5. Analisis Perbandingan Nilai PT dan INR Pasien antara Kondisi Pra dan Pasca Pemberian Ketorolak Selama 5 Hari

\begin{tabular}{ccccc}
\hline Pengukuran VAS & N & Median (minimum-maksimum) & Rerata + S.E. & $\boldsymbol{p}$ \\
\hline Hari I & 20 & $4(2-7)$ & $4 \pm 0,27$ & \\
Hari II & 20 & $3(0-7)$ & $3 \pm 0,48$ & \\
Hari III & 20 & $2(0-5)$ & $1,8 \pm 0,35$ & 0,00 \\
Hari IV & 20 & $0,00(0-3)$ & $0,35 \pm 0,17$ & \\
Hari V & 20 & $0,00(0-3)$ & $0,30 \pm 0,16$ & \\
\hline
\end{tabular}


Keterangan:

Uji Friedman. Uji post-hoc Wilcoxon : Hari I v.s Hari II $p<0,05$; Hari I v.s Hari III $p<$ 0,05; Hari I v.s Hari IV $p<0,05$; Hari I v.s Hari V $p<0,05$; Hari II v.s Hari III $p<0,05$; Hari II v.s Hari IV $p<0,05$; Hari II v.s Hari V $p<0,05$; Hari III v.s Hari IV $p<0,05$; Hari III v.s Hari V $p<0,05$; Hari IV v.s Hari V $p>0,05$.

\section{PEMBAHASAN}

\section{Analisis Fungsi Ginjal}

Dari 20 pasien, 6 pasien tidak mengalami perubahan GFR, sedangkan jumlah pasien yang mengalami peningkatan dan penurunan nilai GFR adalah sama yaitu masing-masing 7 pasien. Berdasarkan hasil uji Wilcoxon, tidak terdapat perbedaan rerata antara nilai GFR pada kondisi pra dan pasca pemberian ketorolak selama 5 hari $(0,68 ; p>0,05)$. Tetapi, 7 dari 20 pasien mengalami penurunan nilai GFR dan sebanyak 1 pasien (5\%) mengalami penurunan GFR sebesar $66,70 \%$ yang mengindikasikam bahwa pasien tersebut mengalami kerusakan ginjal. Tidak ditemukan adanya pasien yang mengalami gagal ginjal.

Hasil ini tidak sesuai dengan beberapa penelitian antara lain yang dilaporkan oleh Rao et al. (1995) bahwa penggunaan ketorolak setelah 5 hari dapat meningkatkan konsentrasi serum kreatinin dari 0,93 \pm 0,17 menjadi 1,22 $\pm 0,39 \mathrm{mg} / \mathrm{dL}$. Kejadian gagal ginjal akut juga dilaporkan terjadi pada 3 pasien yang mendapatkan ketorolak setelah menjalani pembedahan yang bersifat reversible setelah penghentian ketorolak (Haragsim et.al., 1994). Gagal ginjal akut yang diakibatkan oleh ketorolak dapat terjadi disebabkan oleh penghambatan prostaglandin pada ginjal, sehingga menurunkan aliran darah ke ginjal (McEvoy, 2005). Perbedaan hasil yang didapatkan oleh peneliti dapat dikarenakan oleh jumlah sampel yang sedikit. Menurut Myles dan Power pada tahun 1998, kejadian gagal ginjal yang disebabkan oleh penggunaan ketorolak dapat terjadi 1 dalam 1.000 hingga 100.000 pasien.

\section{Analisis Fungsi Hemostasis}

Untuk mengetahui pengaruh pemberian ketorolak terhadp fungsi hemostasis, dilakukan pengujian terhadap keadaan pra dan pasca pemberian ketorolak meliputi: nilai BT, CT, PT, dan INR.

\begin{tabular}{ccc}
\multicolumn{1}{c}{ Dari } & hasil & pengujian \\
menggunakan & metode & Wilcoxon, \\
didapatkan & bahwa & pemberian
\end{tabular}
ketorolak dapat memperpanjang waktu perdarahan dengan nilai signifikansi sebesar 0,04 $(p<0,05) \quad$ meskipun penggunaan ketorolak selama 5 hari tidak memperlihatkan nilai BT yang 
menyimpang dari nilai rujukan normal yaitu 3-8 menit. Mekanisme ketorolak mempengaruhi fungsi koagulasi darah yaitu dengan menghambat kolagen dan asam arakidonat pada jalur eicosanoid (McEvoy, 2005).

Pada pengukuran $\mathrm{CT}$, juga memperlihatkan bahwa penggunaan ketorolak dapat menghambat laju koagulasi darah dengan meningkatkan CT $(0,02 ; p<0,05)$. meskipun begitu, peningkatan nilai $C T$ dari $7,47 \pm 0,13$ menit menjadi 7,95 $\pm 0,09$ tidak memberikan pengaruh klinis yang berarti terhadap pasien.

Pada perbandingan PT dan INR juga memperlihatkan bahwa penggunaan ketorolak dapat mengganggu fungsi koagulasi dengan tingkat signifikansi $0,03(p<0,05)$ untuk PT dan 0,03 $(p<0,05)$ untuk INR.

Dari hasil analisis parameterparameter hemostasis semuanya memperlihatkan bahwa penggunaan ketorolak dapat mengganggu fungsi hemostasis meskipun tidak memberikan pengaruh klinis yang berarti terhadapa pasien.

\section{Analisis Efektivitas Analgetik Ketorolak}

Pengukuran dilakukan menggunakan instrumen VAS yang telah dimodifikasi dan mengkonversi hasilnya ke dalam bentuk angka kemudian diinterpretasikan ke dalam tingkat keparahan nyeri. Untuk skor 0 diinterpretasikan sebagai kondisi tanpa nyeri, 1-5 sebagai nyeri ringan, 5-7 sebagai nyeri sedang dan 7-10 sebagai nyeri hebat. Dapat dilihat pada tabel 8 , Hari pertama hingga hari III pasien rata-rata mengalami nyeri ringan yang terus menurun dari hari ke hari.

Dari pengujian statistik uji Friedman dan post-hoc menggunakan uji Wilcoxon, hanya antara hari ke 4 dan hari ke 5 yang tidak memberikan perbedaan yang bermakna secara statistik $(p>0,05)$. Maka dari itu, dapat dikatakan pada hari IV, rata-rata pasien telah mengalami resolusi atau tidak mengalami nyeri dengan skor VAS 0 (0-3) sehingga pemberian ketorolak dapat diperpendek menjadi 4 hari untuk pasien-pasien yang telah menjalani bedah saraf dan memiliki karakteristik yang sama dengan pasien yang berpartisipasi dalam penelitian ini.

\section{KESIMPULAN}

1. Sebanyak 1 dari 20 pasien (5\%) mengalami penurunan GFR sebesar 120,68 mL/menit/1,73 $\mathrm{m}^{2}$ $(66,70 \%)$.

2. Penggunaan ketorolak selama 5 hari berpengaruh terhadap fungsi 
hemostasis yaitu pemanjangan waktu perdarahan, waktu bekuan darah, waktu protrombin, dan peningkatan nilai International Normalized Ratio.

3. Ketorolak dapat memberikan resolusi nyeri pada hari ke 4 untuk nyeri ringan hingga sedang.

\section{DAFTAR PUSTAKA}

Haragsim, L., Dalal, R., Bagga, H., dan Bastani, B., 1994. Ketorolacinduced acute renal failure and hyperkalemia: Report of three cases. American Journal of Kidney Diseases, 24(4), 578-580.

Lacy, C.F., Armstrong, L.L., Goldman, M.P., Lance, L.L., (ed), 2008, Drug Information Handbook A Comprehensive Resource for all Clinicians and Healthcare Proffesionals, $17^{\text {th }}$ edition, Lexi-comp inc., Canada, (hal. 2007-2014)

McEvoy, G.K., (ed), 2005, AHFS Drug Information, American Society of Health-System Pharmacists, Bethesda. Hal (2007-2014).

Myles, P. S., dan Power, I., 1998. Does ketorolac cause postoperative renal failure: how do we assess the evidence? $\mathrm{Br} J$ Anaesth, 80(4), 420-421.

Rao, D. T. R. K., Naidu, M. U. R., Shobha, J. C., Ravisekhar, K., Rani, P. U., dan Chandrasekhar, E., 1995. Renal Effects of Oral Ketorolac in Patients with Mild to Moderate Pain. Clin. Drug Invest., 9(2), 111-115.

Schug, S.A., Manopas, A., 2007, Update on the Role of NonOpioids for Postoperative Pain Treatment, Best Practice \& Research Clinical Anaesthesiology, Vol. 21 No. 1:15-30.

Scottish Intercollegiate Guidelines Network, 2004, Postoperative management in adults $A$ practical guide to postoperative care for clinical staff, Scottish Intercollegiate Guidelines Network Royal College of Physicians, Edinburgh, United Kingdom, (hal. 28)

Vivian, H.Y., Abrishami, A., Peng, P.W.H., Wong, J., Chung, F., 2009, Predictors of Postoperative Pain and Analgesic Consumption, Anesthesiology, V 111 No. 3:657-677. 